\title{
Characteristics of Commercial Motorcyclists in Benin City: Implications for Road Safety
}

\author{
Okojie $\mathrm{OH}^{a}$, Omuemu $\mathrm{VO}^{a}$ and Ighodaro $\mathrm{JN}^{a}$
}

\begin{abstract}
The aim of this paper is to evaluate the characteristics of commercial motorcyclists in Ugbowo, Benin-city. A cross-sectional and descriptive study was carried out among commercial motorcyclists in Ugbowo, Benin-city, Edo State. A total of 252 commercial motorcyclists were involved in the study. A cluster sampling method was used in selecting respondents in 7 out of the 14 parks in Ugbowo. Majority of the respondents 218 (86.5\%) did not attend any riding school while only 34 (13.5\%) had attended one. One hundred and forty-two (56.4\%) possessed a riding license and only about half of them (51.3\%) wore helmets, $40.9 \%$ wore goggles and $7.8 \%$ had fire extinguishers. None of the respondents provided helmets for their passengers. This study highlighted certain characteristics of commercial motorcyclists that may promote road traffic accidents. Therefore, there is need for mobilisation and sensitisation of commercial motorcyclists and the general public on road safety.
\end{abstract}

\section{INTRODUCTION}

Motorcycling is a relatively inexpensive and convenient means of transportation particularly in the developing countries where roads are in poor condition. ${ }^{1}$ Motorcycling is a popular means of transportation in Nigeria especially in urban areas, as fewer people can maintain their cars for economic reasons and commercial motorcycling is also becoming popular because of the high rate of unemployment. ${ }^{2-3}$

Commercial motorcycling as a means of livelihood is a demanding occupation and

KEY WORDS: Commercial motorcyclists; road safety

Okojie $\mathrm{OH}^{*}$, Omuemu $\mathrm{VO}^{2}$ and Ighodaro $\mathrm{JN}^{*}$, Department of Commuity Health, College of Medicine, University of Benin, P.M.B. 1154, Benin-city, Edo State, Nigeria.

Correspondence: Dr. V.O. Omuemu, Department of Community Health, College of Medicine, University of Benin, P.M.B. 1154, Benin-city, Edo State, Nigeria. Email:cvomuemu@yahoo.com

(0 CMS UNIBEN JMBR 2006; 5(1): 58-63 could be associated with physical and emotional stress which may be expressed as recklessness, violence, intake of alcohol and drugs of addiction. ${ }^{4}$ It has been documented that motorcycling constitutes the highest risk group in road traffic accidents. ${ }^{5-7}$ The factors associated with road traffic accidents can operate at three levels: the agent (vehicle) , the host (road user) and the environment (road condition).$^{8}$ The vehicular factors include inefficient brakes, poor head lamps, lack of horns, worn out tyres, lack of driving mirrors and leg protector bars. The host factors include inadequate training, recklessness, speeding, non-use of safety helmets, disregard for other road users and road signs and riding under the influence of alcohol and drugs. The environmental factors include condition of the road, for example, poorly designed curves, pot holes, lack of road signs, slippery road surfaces, unlit roads and weather conditions such as rainy and hazy weather. Therefore, attempts at prevention and control should 
necessarily be geared towards each of the above named factors.

This study, therefore, is aimed at evaluating the characteristics of commercial motorcyclists in Ugbowo with a view to examining their implications for road safety.

\section{Materials and methods}

This was a cross-sectional and descriptive study carried out in Ugbowo community, one of the ten political wards in Egor Local Government Area of Edo State. The study population included commercial motorcyclists plying the Ugbowo-Iagos road and its environs. Using the formula for calculating sample size for a descriptive, cross-sectional study where minimum sample size =

$$
=\frac{p \times q}{(0.05 / 1.96)^{2}}
$$

and $\mathrm{p}=$ proportion of motorcycles involved in RTAs.

$$
\mathrm{p}=17.8 \%{ }^{9} \text { and } \mathrm{q}=1-\mathrm{p}
$$

We estimated that a total of 225 respondents would be the minimum sample size to provide acceptable precision. However, a total of 252 respondents participated in the study. Cluster sampling was done using a park as a sampling unit. Seven out of the 14 parks in Ugbowo were selected by balloting and all the commercial motorcyclists in the selected parks were included in the study. A structured, interviewer-administered questionnaire was used to collect information on demographic data and other questions directed at the study's objectives such as possession of riding licence, number of passengers carried, alcohol use and drug use. Informed consent was sought and given by respondents. Data was analysed using the SPSS statistical package.

\section{RESULTS}

Table 1 shows the demographic profile of the 252 respondents studied. The respondents were all males and the highest proportion (58.3\%) was in the 25-34 years age group. Mean age for the respondents was $31.4+7.8$ years. The characteristics of the commercial motorcyclists are reflected in Table 2. Majority of the respondents 218 (86.5\%) did not attend any riding school while only 34 (13.5\%) attended one. One hundred and forty two (56.4\%) of the respondents possessed a riding license as opposed to 110 (43.6\%) who did not. Two hundred and sixteen (85.7\%) have been riding for 1-10 years followed by 23 (9.1\%) who had ridden for 11-20 years. The mean duration of riding by respondents was $7.1 \pm 2.2$ years

Table 1: Demographic profile of respondents

\begin{tabular}{lll}
\hline Variables & Frequency & Percentage \\
\hline Age (years) & & \\
$15-24$ & 44 & 17.5 \\
$25-34$ & 147 & 58.3 \\
$35-44$ & 44 & 17.5 \\
$>45$ & 17 & 6.7 \\
Total & 252 & 100.0 \\
Marital Status & & \\
Single & 101 & 40.0 \\
Married & 130 & 51.6 \\
Separated/Divorced & 16 & 6.4 \\
Widowed & 4 & 1.6 \\
No response & 1 & 0.4 \\
Total & 252 & 100.0 \\
Educational Status & & \\
Primary & 45 & 17.9 \\
Secondary & 139 & 55.2 \\
Tertiary & 68 & 26.9 \\
Total & 252 & 100.0 \\
\hline
\end{tabular}


Table 2: Characteristics of commercial motor-cyclists

\begin{tabular}{lll}
\hline Variable & Frequency & Percentage \\
\hline Attendance at driving school & & 13.5 \\
Yes & 34 & 86.5 \\
No & 218 & 100.0 \\
Total & 252 & \\
Possession of a riding license & & 56.4 \\
Yes & 142 & 43.6 \\
No & 110 & 100.0 \\
Total & 252 & \\
No. of passengers carried & & 79.0 \\
1 & 199 & 17.9 \\
2 & 45 & 3.1 \\
No response & 8 & 100.0 \\
Total & 252 & \\
Alcohol use & & 64.7 \\
Yes & 163 & 35.3 \\
No & 89 & 100.0 \\
Total & 252 & \\
Use of psychoactive drugs & & 42.1 \\
Yes & 106 & 57.1 \\
No & 144 & 0.8 \\
No response & 2 & 100.0 \\
Total & 252 & 97.6 \\
Awareness of FRSC & & 2.4 \\
Yes & 246 & 100.0 \\
No & 6 & \\
Total & 252 & \\
\hline
\end{tabular}

Figure 1 and 2 show the daily duration of riding and sleeping among the respondents, respectively. The majority of the respondents, 199 (79.0\%) carry one passenger at a time while 45 (17.9\%) carry two passengers at a time. Concerning the use of personal protective clothing and gadgets, about half of the study population (51.3\%) wore helmets, $40.9 \%$ wore goggles and $7.8 \%$ had fire extinguishers. None of the respondents provided helmets for their passengers. Majority of the respondents, 246 (97.6\%) were aware of the Federal Road Safety Commission while 6 (2.4\%) were not. A higher proportion of the respondents 118 (46.8\%) were not aware of road signs, 101 (40.1\%) claimed there were no road signs available while only 33 (13.1\%) claimed there were road signs. One

\footnotetext{
( CMS UNIBEN JMBR 2006; 5 (1) : 58-63
}

hundred and sixty-three (64.7\%) of the respondents use alcohol while 89 (35.3\%) did not. Of those who take alcohol, 113 (69.3\%) were occasional drinkers, 28 (17.2\%) drink 2.5-12.5 units of alcohol weekly, 20 (12.3\%) drink 15-25 units of alcohol weekly and 2 (1.2\%) drink 27.5-37.5 units of alcohol weekly. (one unit of alcohol $=1 / 2$ bottle of beer $=1$ glass of wine $=1$ short of gin or whisky) .

One hundred and six (42.1\%) of the respondents agreed they used psychoactive drugs as opposed to 144 (57.1\%) who did not. The types of psychoactive drugs used were kolanut (46.4\%), coffee (13.8\%), smuff (8.0\%), Indian hemp (10.2\%) and sedatives (6.5\%) . The reasons for the use of drugs include lack of sleep (24.8\%), fatigue (23.1\%), booty aches and pain (14.5\%), headaches (9.4\%) and dim vision $(2.6 \%)$. 


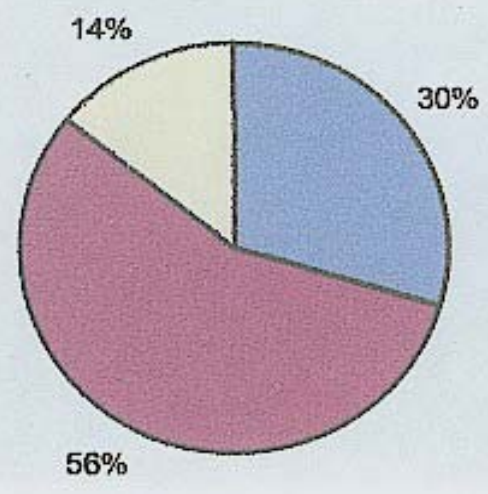

$\square<8 H R S$ 口8-12HRS G $>12$ HRS

Figure 1: Duration of Daily Riding By Respondents

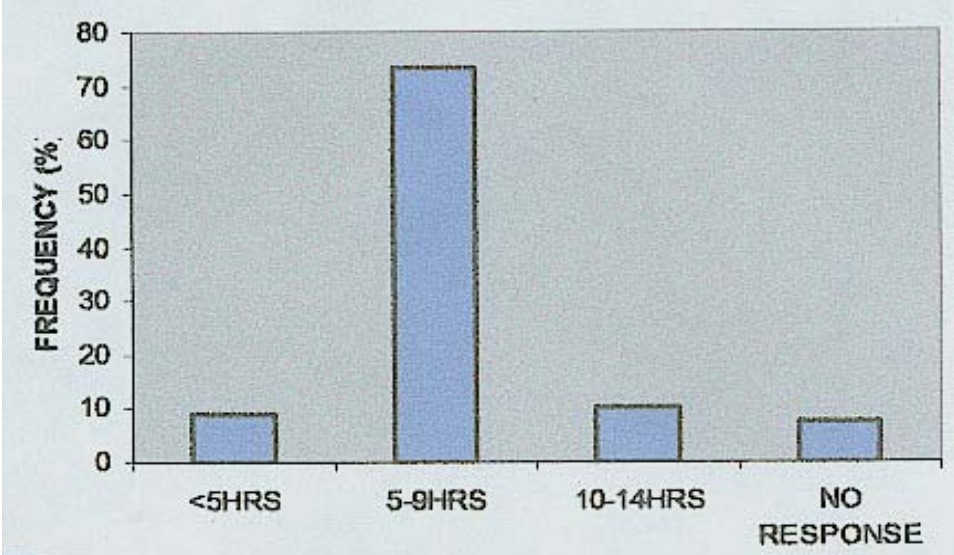

Figure 2: Duration of Sleep (Daily) By Respondents

\section{Discussion}

All the respondents were males and the highest proportion of them were 25-34 years of age, with a mean age of $31.4 \pm 7.8$ years. This is not surprising as the occupation is male dominated and these males are traditionally breadwinners and are more involved in outdoor activities such as commercial motorcycling.

Although $13.5 \%$ of the respondents had attended a riding school, $56.4 \%$ of them possessed a riding licence. This may be evidence that riding licences are issued without proper training. However, this training may have been obtained informally. This pattern was seen among injured motorcyclists attending a Central London Accident and Emergency Unit where only 18\% had received any formal training and 31\% were in possession of a riding licence. ${ }^{10} \mathrm{~A}$ smaller proportion of the respondents carry more than one passenger at a time and this is because carrying more than one passenger is against the law. It was seen in this study that compliance with use of safety devices such as helmets, goggles and fire extinguishers was poor, more so that helmets were not provided for the passengers. This may be because there is no strict enforcement of this law by the responsible agency. It has been documented that the use of helmets recuces the risk of head injury by 88\% and severe brain injury by at least $75 \% .{ }^{11}$ The observation that no passenger used helmets is alarming as the implication 
is that they are totally unprotected and vulnerable to developing head injuries in case of road traffic accidents. Therefore, education to increase community awareness of this safety measure followed by legislation for the compulsory wearing of safety helmets is urged.

While awareness about the Federal Road Safety Commission (FRSC) appeared to be high among the respondents, a small proportion of them were aware of road signs. This could be attributed to the fact that road signs are absent or where they may be present, they are few and often unhelpful to the road users. Majority of the respondents took alcohol and this may be due to the stressful nature of their job. This has implication for road safety because drinking alcohol increases the likelihood of motorcycle crashes starting at blood alcohol levels as low as $0.02 \mathrm{mmol}$ per litre. ${ }^{12}$ More than a third of the respondents used psychoactive drugs and the major reasons for their use were to combat sleep and fatigue. This could lead to impairment of cognitive function and judgement that could contribute to the occurrence of RTAs as has been shown by several studies. ${ }^{13-17}$

This study has highlighted certain characteristics of commercial motorcyclists that might favour or promote RTAs and thereby deleterious to road safety. It is recommended that the appropriate agencies responsible for road safety should embark with all seriousness on sensitization and mobilization of motorcyclists to ensure that they comply with road safety regulations. They should also begin to implement and enforce regulations guiding road safety.

\section{ACKNOWLEDGEMENT}

The authors wish to express their gratitude to all the commercial motorcyclists who participated in the study for their co-operation during the data collection.

\section{References}

1 Loby S, Hassan I, Jahangin N, Rizvi N, Farrooq M, Ubaid S and Sadrudim S. Road traffic injuries in Karachi: the disproportionate role of buses and trucks. S.E. Asia J. Trop. Med. Public Health, 1997; 28: 395-8.

2 Falope IA. Motorcycle accidents in Nigeria: a new group at risk. West Afr. Med. J. 1991; 10: 187-9.

3. Odelowo EO. Pattern of trauma resulting from motorcycle accidents in Nigerians: a two-year prospective study. Afr. J. Med. Sci. 1994; 23: 109-12.

4 Erndad R, Belkin $\mathrm{K}$ and Theorell T. What prevents professional drivers from following physician's cardiology advice? Psychother. Psychosom. 1998; 93: 1543-51.

5. Adesunkanmi AR, Oginni LM, Oyelami OA and Badru OS. Road traffic accidents to African children; assessment of severity using the injury severity score (ISS) . Injury 2000; 31: 225-8.

6. OdelowO EO. Pattern of pedestrian injuries from road traffic accidents in Nigerians. West Afr. Med. J. 1992; 130-4.

7. Pang TV, Umar RS, Azher AA, Ahmed MM, Nasur MT and Harwant S. Accident characteristics of injured motorcyclists in Malaysia. Mal. Med. Assoc. 2002; 1.

8. Asogwa SE. Road traffic accidents in Nigeria: a handbook for all road users. Enugu, Snaap Press Ltd., Enugu. 1999; 34-62.

9. Ogbeide O, Okojie OH, Isah EC and Wagbatsoma V. Road traffic accidents as seen in Benin-city, Nigeria. Niger. Med. J. MarApr 1994; 26 (2) : 45-7.

10. Sweetnam DI, Morris F and Cope A. The injured motorcycle messenger. Arch. Emerg. Med. 1993; 10 (3) : 193-6.

11. Thompson DC and Patterson MQ. Cycle helmets and the prevention of injuries. Sport Medicine, 1998 Apr; $25(4)$ : 213-9.

12. Madden $\mathrm{C}$ and Cole TB. Emergency intervention to break the cycle of drunken driving and recurrent injury. Ann. Emerg. Med. 1995; 26 (2) : 177-9. 
13. Rafindadi AH. A review of types of injuries sustained following road traffic accidents and their prevention. Nig. J. Surg. Research, $2000 ; 2: 3-4$

14. Aguwa $\mathrm{CN}$, Anosike $\mathrm{EO}$ and Akubue PI. Road accidents in Nigeria: level of alcohol in the blood of automobile drivers. Centr. Afr. J. Med. 1982; 28: 171-4.

15. Hijar M, Flores M, Lopez MV and Rosovsky H. Alcohol intake and severity of injuries on highways in Mexico: a comparative analysis. Addiction, 1998; 93: 1543-51.
16. Mao Y, Zhang J, Robbins G, Clarke K, Lam $M$ and Pickett $W$. Factors affecting the severity of motor vehicle traffic crashes involving young drivers in Ontario. Inj. Prev. 1997; 3: 183-9.

17. Albery IP, Strang J, Gossop M and Griffiths P. Illicit drugs and driving: prevalence, belief and accident involvement among a cohort of current out of treatment drug users. Drug Alco. Depend. 2000; 58: 197-204. 